\title{
HABILIDADES DE ALFABETIZAÇÃO EM SAÚDE DE IDOSOS DE COMUNIDADES VULNERÁVEIS
}

Andreivna Kharenine Serbim; Universidade Federal de Alagoas; andreivna.serbim@arapiraca.ufal.br Naiana Oliveira dos Santos; Universidade Franciscana; naiaoliveira07@gmail.com Ana Cláudia Fuhrmann; Universidade Federal do Rio Grande do Sul; ana_fuhrmann@hotmail.com Lisiane Manganelli Girardi Paskulin; Universidade Federal do Rio Grande do Sul; paskulin@ufrgs.br

\section{RESUMO}

Introdução: $\mathrm{O}$ conceito da alfabetização em saúde é relativamente novo no Brasil e está relacionado às habilidades das pessoas em entender aspectos do autocuidado e dos cuidados no sistema de saúde para tomar decisões adequadas. Objetivo: Descrever as experiências dos idosos em acessar, compreender, comunicar e avaliar a informação em saúde no contexto da atenção primária. Métodos: Estudo qualitativo com 42 idosos em duas unidades de saúde de comunidades vulneráveis do município de Arapiraca/Alagoas. Entrevistas semiestruturadas foram norteadas pelo instrumento Health Literacy, adaptado para uso no Brasil. O software NVivo 11.0 foi utilizado para organização das respostas. Para a análise temática, estabeleceu-se previamente como categorias as questões que compõem o instrumento. Estudo aprovado por Comitê de Ética (CAAE: 72106817.2.0000.5347). Resultados: Emergiram os temas: acesso a informações sobre saúde, compreensão das informações sobre saúde, comunicação das informações sobre saúde e impactos das informações sobre a saúde. Os idosos apresentavam dificuldades para exercer o empoderamento, o pensamento crítico e o gerenciamento das condições de saúde. Os participantes tinham conhecimento limitado sobre a condição de saúde, considerando que a maioria lidava com uma condição crônica. Muitos demonstravam estar acostumados ao não recebimento da informação em saúde e apoiavam-se em outras fontes que não eram os profissionais de saúde. Conclusões: Os achados evidenciam a necessidade de intervenções de alfabetização em saúde direcionadas a idosos. Ainda, o sistema de saúde deve buscar reduzir as demandas e as complexidades impostas aos idosos, direcionando intervenções para a construção de habilidades e de capacidades ao longo da vida.

Palavras-chave: Letramento em saúde; Saúde do idoso; Educação em saúde; Atenção primária à saúde; Promoção da saúde.

Agradecimentos: O presente trabalho foi realizado com apoio do Conselho Nacional de Desenvolvimento Científico e Tecnológico (CNPq). 